\section{Comparison of functional outcomes after robot-assisted laparoscopic sacrocolpopexy in women with a BMI below and above 30}

\author{
Thibault Thubert, ${ }^{1,2}$ Yohann Dabi, ${ }^{2}$ \\ Anne Sophie Boudy, ${ }^{2}$ Marion Joubert, ${ }^{1}$ \\ Christophe Vaessen, ${ }^{3}$ \\ Emmanuel Chartier-Kastler, ${ }^{3}$ \\ Jean-Pierre Lefranc, ${ }^{1}$ Morgan Rouprêt ${ }^{3}$ \\ ${ }^{1}$ Division of Gynaecologic Surgery, Pitié \\ Salpétrière Hospital, APHP, Paris; \\ ${ }^{2}$ Obstetrics, Gynaecology and \\ Reproductive Medicine Department, \\ Antoine Béclère Hospital, Clamart; \\ ${ }^{3}$ Academic Department of Urology, Pitié \\ Salpétrière Hospital, APHP, Paris, \\ France
}

\begin{abstract}
The aim of this study was to assess the impact of body-mass index on robot-assisted laparoscopic sacrocolpopexy (RALSCP). A retrospective study was conducted on women who underwent a RALSCP. Data were collected prospectively from 17 obese and 78 non-obese patients treated between January 2008 and January 2013. Obesity was defined as a body-mass index (BMI) of $\geq 30 \mathrm{~kg} / \mathrm{m}^{2}$. Relationships with outcome analysed using MannWhitney U-test and Fisher's exact test. The operating time was the same in both groups: $220 v s 200 \mathrm{~min}$ in the obese and non-obese groups, respectively $(\mathrm{P}=0.232)$. The median follow-up was 12 months in both non-obese and obese patients. Overall anatomic repair rate was $94.1 \%$ and $97.4 \%$ for obese and non-obese patients, respectively $(\mathrm{P}=0.95)$. The overall reoperation rate (including surgery for de novo urinary-stress incontinence) was $5.9 \%$ for obese vs $11.5 \%$ for non-obese patients $(\mathrm{P}=0.8)$. These findings suggest that RALSCP is a viable option for obese women. The complication rates and outcomes for obese women were similar to those for non-obese women.
\end{abstract}

\section{Introduction}

Obesity and pelvic-floor disorders are both increasing medical situations. ${ }^{1}$ In 2008 , the prevalence of obesity among US adults was $>30 \%$, while the age-adjusted combined prevalence among women who were overweight (BMI 25-30) and obese (BMI $\geq 30$ ) was $64.1 \% .{ }^{1}$ In 2010, an estimat- ed $17 \%$ of adults were obese in the European Union. ${ }^{2}$ Obesity and, especially, morbid obesity (a BMI $>40.0 \mathrm{~kg} / \mathrm{m}^{2}$ ) is associated with a relative risk of death of $1.62(1.40-1.85$, IC 95\%) as compared to those with a normal BMI. ${ }^{3}$ Although previous studies have reported a correlation between obesity and pelvic-organ prolapse (POP), there is still ongoing debate on this association. ${ }^{4,5}$ As the prevalence of obesity and discomfort from POP is increasing in the Western world, it is important for surgeons to know how to manage such patients. In obese women, surgery may be associated with an increased risk of both perioperative and postoperative complications. ${ }^{6}$ Open abdominal sacrocolpopexy has been established as gold-standard procedure to correct prolapse of the anterior and/or apical vaginal-wall compartments. However, a minimally invasive laparoscopic approach has been developed over recent years, and has been shown to be comparable to surgery in terms of functional outcome whilst also demonstrating all the advantages of laparoscopy. ${ }^{8}$ Since 2004, a robot-assisted laparoscopic approach for sacrocolpopexy (RALSCP) has been suggested to be a viable alternative to a purely laparoscopic technique. ${ }^{9-11}$ To date, however, there are no specific data available concerning the results of RALSCP in obese women. The aim of our study, therefore, was to compare the functional outcomes associated with RALSCP in women with a BMI either below or above 30 .

\section{Materials and Methods}

\section{Population}

In this study, we retrospectively reviewed all the prospective data from female patients who had undergone RALSCP between January 2008 and January 2013 and who had attended two tertiary care centers in France. The following data were extracted from their charts: age at the time of surgery, BMI, menopause status, initial stage of genital prolapse (according to the Baden Walker classification), ${ }^{12}$ past medical history, obstetric and surgical histories, past prolapse treatment(s), date of the sacrocolpopexy procedure, operative and perioperative data, complications, anatomical results, and functional results.

Each patient underwent a preoperative work-up for urine analysis, a Pap smear, a pelvic ultrasonography, and urodynamic studies. Objective assessment of POP was carried out using a split speculum during a Valsalva maneuver in the gynecological position, following the Baden Walker. ${ }^{12}$
Correspondence: Yohann Dabi, Obstetrics, Gynaecology and Reproductive Medicine Department, Antoine Béclère Hospital, 157 rue de la Porte de Trivaux, 92140 Clamart, France. Fax: +33145374963

E-mail: yohann.dabi@gmail.com

Key words: Genital prolapse; laparoscopy; morbidity; outcomes; robotics.

Conflict of interest: the authors declare that they have no conflict of interest.

Ethical approval: all procedures performed in studies involving human participants were in accordance with the ethical standards of the institutional and/or national research committee and with the 1964 Helsinki declaration and its later amendments or comparable ethical standards. The Ethics Committee of the Assistance Publique-Hôpitaux de Paris (APHP) (i.e., IRB approval) approved the study. Ethics board approval number: CEROG-GYN 2014-0202R01

Received for publication: 11 May 2016.

Revision received: 13 December 2016.

Accepted for publication: 27 January 2017.

This work is licensed under a Creative Commons Attribution NonCommercial 4.0 License (CC BY-NC 4.0).

CCopyright T. Thubert et al., 2017

Licensee PAGEPress, Italy

Urogynaecologia 2017; 30:178

doi:10.4081/uij.2017.178

Each surgeon performed a prolapse-reduction maneuver using sponge-holding forceps in order to reveal the possible presence of masked urinary-stress incontinence.

Operative and perioperative data included the concomitant surgical procedure (subtotal hysterectomy or mid-urethral sling); conversion to a laparotomy or a vaginal procedure; length of the operation; blood loss; type of analgesia (according to the WHO classification); occurrence of complications; analgesic requirements; and length of hospital stay. The Ethics Committee of the Assistance PubliqueHôpitaux de Paris (AP-HP) (i.e., IRB approval) approved the study and the Principes of the Declaration of Helsinki were respected.

\section{Surgical procedure}

All procedures were achieved using a three-arm da Vinci ${ }^{\circledR}$ surgical system using a trans-peritoneal four-port technique, as described previously. ${ }^{13}$ Two surgeons performed a RALSCP on all women. After identifying the right ureter, the left iliac 
vein, and the iliac-vessel junction, the peritoneum over the sacral promontory was incised medial to the right ureter and lateral to sigmoid colon. For placement of the posterior mesh, dissection of the recto-vagina was performed down to the level of the levator ani muscles, and a mesh was placed and sutured with non-absorbable sutures along the full length of the posterior vaginal wall and into the levator ani muscles. The upper extremity of the anterior mesh was sutured to the anterior vertebral ligament at the level of the sacral promontory with a non-absorbable suture. Complete peritonization of the meshes was achieved by opposing the edges of peritoneum using an absorbable suture.

Surgical time was classified as either "strict operating time" (time for port insertion plus the procedure, but excluding preparation and docking of the robot) or as "overall operating time" (total time in operating theatre).

\section{Complications}

Regarding surgical complications, we have respected the 10 criteria proposed by Martin et al. in 2002 and, especially, the International Urogynecological Association /International continence society (IUGA/ICS), as stated in the European Guidelines. ${ }^{14,15}$

\section{Follow-up}

Follow-up visits were at 6 and 12 months postoperatively, and then every year. At these visits, POP was assessed using the Baden Walker classification.
Surgery was considered successful if the patient was symptomatically satisfied and if the POP score was below stage 2 .

\section{Statistical analyses}

Statistical analyses of the data were performed using R statistical software (Bell Laboratories, Lucent Technologies, Paris, France). Descriptive statistics are shown as medians and IQRs (interquartile range). The Mann-Whitney U-test was used to compare continuous variables, and Fisher's exact test compared categorical variables. A P-value of $<0.05$ was considered statistically significant.

\section{Results \\ Population}

In all, 95 women underwent RALSCP during the study period: 17 women were in the obese group and 78 in the non-obese group. The median BMI in the obese group was 32 (IQR 30.4-34.1) versus 23.6 (IQR 22.2-25.4) in the non-obese group $(\mathrm{P}<0.0001)$. All other characteristics did not significantly vary different between the two groups (Table 1).

\section{Surgery}

The surgical data are shown in Table 2. No significant difference was observed between the groups concerning a concomitant procedure, such as subtotal hysterectomy or a mid-urethral sling. Two meshes (anterior and posterior) were placed in 17 $(100 \%)$ of the obese women and in 76
$(97.4 \%)$ of the non-obese women $(\mathrm{P}=0.79)$. An isolated anterior mesh was placed in two $(2.56 \%)$ women from the non-obese group. Perioperative complication rates were similar for the two groups (Table 3). Bladder injury occurred in three women $(3.8 \%)$ who were all in the non-obese group $(\mathrm{P}=0.95)$. Conversion to abdominal laparotomy was required for one patient $(5.9 \%)$ in the obese group because of pneumoperitoneum intolerance.

\section{Outcomes and complications}

The median follow-up period was 12 months for both groups: IQR 6-19.75 for non-obese and IQR 7-15 in the obese group $(\mathrm{P}=0.86)$. The overall anatomic repair rate was $94.1 \%$ and $97.4 \%$ for obese and nonobese groups, respectively $(\mathrm{P}=0.95)$. During the follow-up, a gynecological examination revealed that prolapse of the posterior compartment had recurred in one patient from the obese group after 12 months, and one prolapse had recurred in the anterior compartment in the non-obese group. Both these women underwent a subsequent procedure via the vaginal route.

Table 4 shows the operative complications as assessed using the ICS/IUGA classification. No significant difference was observed in complication rates between the two groups using ICS/IUGA classification. The following adverse outcomes were reported during the follow-up in obese and non-obese groups, respectively: urinary infections $(0 / 17$ vs $8 / 78, \mathrm{P}=0.37)$, chronic pelvic pain $(0 / 17$ vs $2 / 78, \mathrm{P}=0.79)$, straining to defecate $(0 / 17$ vs $1 / 78, \mathrm{P}=0.39)$, constipation $(0 / 17$ vs $2 / 78, \mathrm{P}=0.79)$, and de novo uri-

Table 1. Patient's characteristics [values are given as median (IQR) [range], number (percentage), or median (IQR) unless otherwise stated].

\begin{tabular}{|c|c|c|c|}
\hline Characteristic & $\begin{array}{l}\text { Obese group } \\
(n=17)\end{array}$ & $\begin{array}{c}\text { Non-obese group } \\
(\mathrm{n}=78)\end{array}$ & P-value \\
\hline BMI & $32(30.4-34.1)[30-36]$ & $23.6(22.2-25.4)$ [18.7-28.4] & $<0.0001^{\circ}$ \\
\hline Age, $y$ & $63(56-69)$ & $64(56.2-69.7)$ & $0.63^{\circ}$ \\
\hline Parity, $n$ & $3(1-3)$ & $2(2-3)$ & $0.54^{\#}$ \\
\hline Postmenopausal status & $15(88.2 \%)$ & $66(84.6 \%)$ & $0.99^{\#}$ \\
\hline Tobacco use & $0(0 \%)$ & $11(14.1 \%)$ & $0.22^{\#}$ \\
\hline Previous cesarean delivery & $3(17.6 \%)$ & $3(3.9 \%)$ & $0.12^{\#}$ \\
\hline Previous hysterectomy & $4(23.5 \%)$ & $7(9 \%)$ & $0.20^{\#}$ \\
\hline Previous POP surgery & $2(11.8 \%)$ & $6(7.7 \%)$ & $0.95^{\#}$ \\
\hline $\begin{array}{l}\text { POP stage (Baden Walker) } \\
\text { Stage } 0-1 \\
\text { Stage } 2 \\
\text { Stage } 3-4\end{array}$ & $\begin{array}{c}0(0 \%) \\
2(11.8 \%) \\
15(88.2 \%)\end{array}$ & $\begin{array}{c}0(0 \%) \\
5(6.4 \%) \\
73(93.6 \%)\end{array}$ & $\begin{array}{l}\mathrm{NS}^{\#} \\
0.95^{\#} \\
0.8^{0 \S}\end{array}$ \\
\hline SUI (11.8\%) & $16(20.5 \%)$ & $0.62 \#$ & \\
\hline Masked SUI* & $10(58.9 \%)$ & $35(44.8 \%)$ & $0.60 \#$ \\
\hline
\end{tabular}

BMI, body mass index (calculated as weight in kilograms divided by the square of height in meters); ICS, International Continence Society; IQR, interquartile range; POP, pelvic organ prolapse; POP-Q, pelvic organ prolapse quantification grading system; SUI, urinary stress incontinence. ${ }^{*}$ Patients without obvious urinary stress incontinence; ${ }^{\circ}$ Welch 2-sample $t$ test (Student's $t$ test); ${ }^{*}$ Pearson's $X^{2}$ test with Yates continuity correction ( $\mathrm{X}^{2}$ test). 
nary incontinence $(3 / 17$ vs $10 / 78, \mathrm{P}=0.89)$. We observed erosion of two meshes in the non-obese group, which occurred at 9 and 20 months after surgery for the mid-urethral sling and the anterior vaginal mesh, respectively. The overall reoperation rate (including surgery for de novo urinary-stress incontinence) was $5.9 \%$ for the obese group versus $11.5 \%$ for the non-obese group $(\mathrm{P}=0.8)$.

\section{Discussion}

The ultimate aim of our study was to determine the impact of BMI on the outcome of RALSCP. We have reported that the overall anatomic repair rate was $94.1 \%$ and $97.4 \%$ for obese and non-obese groups, respectively $(\mathrm{P}=0.95)$. Moreover, no significant difference was observed in complication rates between the groups.

The current opinion is that obese patients are at higher risk of morbidity. A few previous studies have found that abdominal surgery for a gynecologic benign condition (other than POP) is associated with a greater incidence of wound infection in obese women compared to non-obese women. ${ }^{6,16,17}$ In contrast, vaginal surgery for a hysterectomy or POP in obese women is associated with less morbidity than abdominal surgery in terms of blood transfusions or urinary retention. ${ }^{18}$

Table 2. Operative data for laparoscopic sacrocolpopexy [values are given as number (percentage) or median (interquartile range)].

\begin{tabular}{|c|c|c|c|}
\hline $\begin{array}{l}\text { Characteristic } \\
(\mathrm{n}=17)\end{array}$ & $\begin{array}{l}\text { Obese group } \\
\quad(n=78)\end{array}$ & Non-obese group & P-value \\
\hline Concomitant subtotal hysterectomy & $2(15.38 \%)^{*}$ & $1(1.41 \%)^{*}$ & $0.126^{\circ}$ \\
\hline Concomitant midurethral sling & $11(64.71 \%)$ & $43(55.1 \%)$ & $0.651^{\circ}$ \\
\hline $\begin{array}{l}\text { Mesh location } \\
\text { Anterior mesh only } \\
\text { Posterior mesh only } \\
\text { Both anterior and posterior meshes }\end{array}$ & $\begin{array}{c}0(0 \%) \\
0(0 \%) \\
17(100 \%)\end{array}$ & $\begin{array}{c}2(2.56 \%) \\
0(0 \%) \\
76(97.44 \%)\end{array}$ & $\begin{array}{l}0.791^{\circ} \\
\mathrm{NS}^{\circ} \\
0.791^{\circ}\end{array}$ \\
\hline Operative duration, min & $220(170-320)[125-370]$ & $200(150-247.5)[90-410]$ & $0.232^{\#}$ \\
\hline Length of hospital stay, days & $4(4-5)$ & $4(3-5)$ & $0.541^{\#}$ \\
\hline
\end{tabular}

*Patients without previous urinary hysterectomy; ${ }^{\circ}$ Pearson's $\chi^{2}$ test with Yates continuity correction $\left(\chi^{2}\right.$ test); *Welch 2-sample $t$ test (Student's $t$ test).

Table 3. Complications and outcome.

\begin{tabular}{|c|c|c|c|}
\hline & Obese & Non obese & P-value* \\
\hline No. 17 & 78 & & \\
\hline $\begin{array}{l}\text { Bladder injury n (\%) } \\
\text { Laparoconversion } \mathrm{n}(\%) \\
\text { Urinary infection } \mathrm{n}(\%) \\
\text { Eventration } \\
\text { Reoperation for immediate complications (C1) } \\
\text { Reoperation for urinary incontinence (C2) n (\%) } \\
\text { Reoperation for mesh exposure (C3) n (\%) } \\
\text { Reoperation for recurrent prolapse (C4) n (\%) } \\
\text { Global reoperation rate }(\mathrm{Cl}+\mathrm{C} 2+\mathrm{C} 3+\mathrm{C} 4) \mathrm{n}(\%)\end{array}$ & $\begin{array}{c}0(0 \%) \\
1(5.9 \%) \\
0(0 \%) \\
0(0 \%) \\
0(0 \%) \\
0(0 \%) \\
0(0 \%) \\
1(5.9 \%) \\
1(5.9 \%)\end{array}$ & $\begin{array}{l}3(3.8 \%) \\
0(0 \%) \\
8(10.2 \%) \\
1(1.3 \%) \\
1(1.3 \%) \\
5(6.4 \%) \\
2(2.6 \%) \\
1(1.3 \%) \\
9(11.5 \%)\end{array}$ & $\begin{array}{l}0.95 \\
0.39 \\
0.37 \\
0.39 \\
0.39 \\
0.64 \\
0.79 \\
0.79 \\
0.8\end{array}$ \\
\hline $\begin{array}{l}\text { Post-operative POP stage (Baden Walker) n (\%) } \\
\text { Stage 0-1 } \\
\text { Stage } 2 \\
\text { Stage 3-4 }\end{array}$ & $\begin{array}{c}16(94.1 \%) \\
0(0 \%) \\
1(5.9 \%)\end{array}$ & $\begin{array}{l}76(97.4 \%) \\
1(1.3 \%) \\
1(1.3 \%)\end{array}$ & $\begin{array}{l}0.95 \\
0.39 \\
0.79\end{array}$ \\
\hline $\begin{array}{l}\text { Post operative de novo functional disorders } \\
\text { Constipation } \\
\text { Straining to defecate } \\
\text { Straining to void } \\
\text { Stress urinary incontinence } \\
\text { Urge incontinence }\end{array}$ & $\begin{array}{c}0(0 \%) \\
0(0 \%) \\
1(5.9 \%) \\
3(17.6 \%) \\
0(0 \%)\end{array}$ & $\begin{array}{l}2(2.6 \%) \\
1(1.3 \%) \\
5(6.4 \%) \\
9(11.5 \%) \\
1(1.3 \%)\end{array}$ & $\begin{array}{l}0.79 \\
0.39 \\
0.64 \\
0.78 \\
0.39\end{array}$ \\
\hline
\end{tabular}

*Pearson's Chi-squared test with Yates' continuity correction (Chi-squared test). ICS, international continence society; n, number; POP, pelvic organ prolapse.

Table 4. Operative complications using IUGA/ICS classification.

\begin{tabular}{lccc} 
& Obese & Non obese & P-value* \\
T1 complications & $1(7 \mathrm{~B} / \mathrm{T} 1 / \mathrm{S} 5)$ & $3(4 \mathrm{~A} / \mathrm{T} 1 / \mathrm{S} 5)$ & 0.77 \\
T2 complications & - & $8(4 \mathrm{~B} / \mathrm{T} 2 / \mathrm{S} 5)$ & 0.36 \\
& $1(1 \mathrm{~B} / \mathrm{T} 4 / \mathrm{S} 2)$ & $1(\mathrm{~B} / \mathrm{T} 2 / \mathrm{S} 3)$ & 0.95 \\
\hline T4 complications & & $1(2 \mathrm{~B} / \mathrm{T} 4 / \mathrm{S} 1)$ & \\
& & & \\
\hline
\end{tabular}

*Pearson's Chi-squared test with Yates' continuity correction (Chi-squared test). 
In the literature, there are some discrepancies concerning the impact of BMI on RALSCP outcomes. Ploumidis et al. did not find a correlation between laparo-conversion and a high BMI: $50 \%$ of their patients had a BMI $>29$, suggesting that moderate obesity does not represent a contraindication for the robotic approach. ${ }^{19}$ In contrast, Gadonneix et al. report a higher risk of conversion when RALSCP was performed in patients with high BMI. ${ }^{20}$

Two retrospective studies have evaluated POP surgery outcomes using an abdominal approach (laparotomy or laparoscopy) according to the patient's BMI. A low rate of complications among obese patients and good anatomic results after a short-term follow-up were found. ${ }^{21,22}$

In the present study, the operating time was the same in both groups: 220 vs 200 min in the obese and non-obese groups, respectively $(\mathrm{P}=0.232)$. Two retrospective studies have already evaluated the technical feasibility of sacrocolpopexy by laparotomy and also laparoscopy among obese patients. ${ }^{21,22}$ Both techniques are available for obese women: the only difference is length of surgery. Considering the laparotomy approach, Bradley et al. ${ }^{21}$ found that operating times were significantly longer for obese women than non-obese women (189 vs 169 min; $\mathrm{P}=0.02$ ). In contrast, operating times reported in the laparoscopic study were similar for obese vs non-obese women, respectively, at 190 vs $180 \mathrm{~min}$; $\mathrm{P}=0.12$. In both studies, the number of concurrent procedures for urinary-stress incontinence or hysterectomy was similar in both groups. ${ }^{22}$

The ideal surgical approach, and especially the functional results, must be as minimally invasive as possible. To fulfill this criterion, ideal POP repair should be by laparoscopy or robot-assisted laparoscopy. However, laparoscopic sacrocolpopexy has not been widely adopted as it demands skill and motivation, and is associated with a long learning curve. ${ }^{23}$ Consequently, robotic-assisted surgery was developed to simplify the laparoscopic approach. This technique added three-dimensional vision and 7 degrees of freedom, which simplified complex laparoscopic tasks, such as suturing and knot tying.

We have hypothesized that roboticassisted laparoscopy is of potential benefit for obese women because of the loss of ergonomy using the laparoscopic approach, due to the thickness of the abdominal wall. In the literature, only one retrospective study has specifically evaluated the impact of BMI in robot-assisted laparoscopy. Perioperative outcomes of 442 patients, who underwent robotic-assisted laparoscop- ic hysterectomy for a benign or malignant condition, were analyzed according to BMI. Overall, no significant difference was found regarding operative time, estimated blood loss, length of hospital stay, and complication rates. ${ }^{24}$

To the best of acknowledge, ours is the first retrospective study to report the impact of obesity on the use of robotic laparoscopic-assisted sacrocolpopexy. To conclude, RALSCP can be an alternative to the laparoscopic approach for obese women for a non-experienced laparoscopic surgeon, even if the operating time for RALSCP is longer than for laparoscopy. Because the posterior approach in obese patients significantly contributes to the difficulty and length of this procedure, the longer operating time for RASCLP, compared to laparoscopic sacrocolpopexy, is because of the lower number of posterior prosthesis mesh placements among obese patients. ${ }^{22}$ Moreover, docking times were not included in our study: this procedure increases anesthesia time by $\sim 15 \mathrm{~min}$.

In the present study, two meshes (anterior and posterior) were placed in all of the obese women and in $97.4 \%$ of the nonobese women $(\mathrm{P}=0.791)$. Even if the posterior approach in obese patients significantly contributes to the difficulty and length of this procedure, we preferred to systematically place a posterior mesh in cases of hypothetical de novo posterior compartment prolapse. Although the impact of obesity on pelvic-floor disorders is well established for urinary and anal incontinence, the association between POP and obesity is still widely debated. The association between obesity and symptoms of pelvic-floor discomfort varies within the literature, which most likely reflects the use of different methodologies. ${ }^{5}$ Some researchers have not found obesity to be an independent risk factor for prolapse progression., ${ }^{4,5,21}$ Conversely, others have found that being overweight or obese was strongly associated with a high rate of global prolapse (OR 2.09; CI95\% 1.1-3.6); ${ }^{4}$ however, these investigators did not perform a physical examination with a speculum or compare their results with a control group of non-obese women. Because increased abdominal pressure (as observed for obese women) is probably a risk factor for genital prolapse, we hypothesize that correction of the anterior compartment in this population could modify the posterior compartment and provoke a de novo prolapse of the posterior compartment. Although the authors of the laparotomy sacrocolpopexy study did not describe if they did or did not place a concomitant anterior and posterior mesh, ${ }^{21}$ they only used a posterior mesh if the patient already had a posterior-compartment prolapse. ${ }^{22}$

A limitation of our study is the short duration of follow-up. An extended period of follow-up is needed to confirm long-term findings, even when obesity is not considered to be a factor affecting the recurrence of POP. A large prospective study is needed to confirm the feasibility of RALSCP, which will enable comparisons between the performance of the vaginal route and the laparoscopic approach to treat POP in obese women. As the prevalence of obesity, aging, and discomfort from POP is increasing in high-income countries, it is important that surgeons know how to manage such patients. Another limitation of our study is the small number of obese patients we could include, which emphasizes the fact our results should be confirmed by a large size randomized controlled trial. Indeed, the number of surgical interventions for POP will increase substantially over the next 40 years.$^{25}$

\section{Conclusions}

The findings from our study suggest that RALSCP is a viable option for obese women with similar functional results than those for non-obese patients. Our results should be confirmed by a large randomized controlled trial.

\section{References}

1. Flegal KM, Carroll MD, Ogden CL, Curtin LR. Prevalence and trends in obesity among US adults, 1999-2008. JAMA 2010;303:235-41.

2. Van Vliet-Ostaptchouk JV, Nuotio M-L, Slagter SN, et al. The prevalence of metabolic syndrome and metabolically healthy obesity in Europe: a collaborative analysis of ten large cohort studies. BMC Endocr Disord 2014;14:9.

3. Calle EE, Thun MJ, Petrelli JM, et al. Body-mass index and mortality in a prospective cohort of U.S. adults. N Engl J Med 1999;341:1097-105.

4. Whitcomb EL, Lukacz ES, Lawrence $\mathrm{JM}$, et al. Prevalence and degree of bother from pelvic floor disorders in obese women. Int Urogyn J 2008;20:289-94

5. Washington BB, Erekson EA, Kassis NC, Myers DL. The association between obesity and stage II or greater prolapse. Am J Obstet Gynecol 2010;202:503.e1-4.

6. Dindo D, Muller MK, Weber M, Clavien P-A. Obesity in general elec- 
tive surgery. Lancet 2003;361:2032-5.

7. Culligan PJ, Murphy M, Blackwell L, et al. Long-term success of abdominal sacral colpopexy using synthetic mesh. Am J Obstet Gynecol 2002;187:147380; discussion 1481-2.

8. Rozet F, Mandron E, Arroyo C, et al. Laparoscopic sacral colpopexy approach for genito-urinary prolapse: experience with 363 cases. Eur Urol 2005;47:230-6.

9. Daneshgari F, Kefer JC, Moore C, Kaouk J. Robotic abdominal sacrocolpopexy/sacrouteropexy repair of advanced female pelvic organ prolaspe (POP): utilizing POP-quantificationbased staging and outcomes. BJU Int 2007;100:875-9.

10. Elliott DS, Krambeck AE, Chow GK. Long-term results of robotic assisted laparoscopic sacrocolpopexy for the treatment of high grade vaginal vault prolapse. J Urol 2006; 176:655-9.

11. Di Marco DS, Chow GK, Gettman MT, Elliott DS. Robotic-assisted laparoscopic sacrocolpopexy for treatment of vaginal vault prolapse. Urology 2004;63: 373-6.

12. Baden WF, Walker TA. Genesis of the vaginal profile: a correlated classification of vaginal relaxation. Clin Obstet Gynecol 1972;15:1048-54.

13. Seror J, Yates DR, Seringe E, et al. Prospective comparison of short-term functional outcomes obtained after pure laparoscopic and robot-assisted laparoscopic sacrocolpopexy. World J Urol 2012;30:393-8.

14. Mitropoulos D, Artibani W, Graefen M, et al. Reporting and grading of complications after urologic surgical procedures: an ad hoc EAU guidelines panel assessment and recommendations. Eur Urol 2012;61:341-9.

15. Haylen BT, Freeman RM, Swift SE, et al. An International Urogynecological Association (IUGA)/International Continence Society (ICS) joint terminology and classification of the complications related directly to the insertion of prostheses (meshes, implants, tapes) and grafts in female pelvic floor surgery. Neurourol Urodyn 2011;30:2-12.

16. Myles TD, Gooch J, Santolaya J. Obesity as an independent risk factor for infectious morbidity in patients who undergo cesarean delivery. Obstet Gynecol 2002;100:959-64.

17. Chen CCG, Collins SA, Rodgers AK, et al. Perioperative complications in obese women vs normal-weight women who undergo vaginal surgery. Am J Obstet Gynecol 2007;197:98.e1-8.

18. Nam K-H, Jeon M-J, Hur H-W, et al. Perioperative and long-term complications among obese women undergoing vaginal surgery. Int J Gynecol Obstet 2010;108:244-6.

19. Ploumidis A, Spinoit A-F, De Naeyer G, et al. Robot-assisted sacrocolpopexy for pelvic organ prolapse: surgical technique and outcomes at a single highvolume institution. Eur Urol 2014;65:138-45.

20. Gadonneix P, Ercoli A, Salet-Lizée D, et al. Laparoscopic sacrocolpopexy with two separate meshes along the anterior and posterior vaginal walls for multicompartment pelvic organ prolapse. J Am Assoc Gynecol Laparosc 2004;11:29-35.

21. Bradley CS, Kenton KS, Richter HE, et al. Obesity and outcomes after sacrocolpopexy. Am J Obstet Gynecol 2008;199:690.e1-8.

22. Thubert T, Naveau A, Letohic A, et al. Outcomes and feasibility of laparoscopic sacrocolpopexy among obese versus non-obese women. Int J Gynaecol Obstet 2013;120:49-52.

23. Mustafa S, Amit A, Filmar S, et al. Implementation of laparoscopic sacrocolpopexy: establishment of a learning curve and short-term outcomes. Arch Gynecol Obstet 2012;286:983-8.

24. Gallo T, Kashani S, Patel DA, et al. Robotic-assisted laparoscopic hysterectomy: outcomes in obese and morbidly obese patients. JSLS 2012;16:421-7.

25. Wu JM, Kawasaki A, Hundley AF, et al. Predicting the number of women who will undergo incontinence and prolapse surgery, 2010 to 2050. Am J Obstet Gynecol 2011;205:230.e1-5. 